\title{
CORRECTION
}

\section{Comparisons between intragastric and small intestinal delivery of enteral nutrition in the critically ill: a systematic review and meta-analysis}

\author{
Adam M Deane ${ }^{1,2^{*}}$, Rupinder Dhaliwal ${ }^{3}$, Andrew G Day ${ }^{3}$, Emma J Ridley ${ }^{4}$, Andrew R Davies ${ }^{4}$ and Daren K Heyland ${ }^{3}$ \\ See related research by Deane et al., http://ccforum.com/content/17/3/R125
}

After publication of this article [1], the authors noticed that their names were listed incorrectly as M Deane Adam, Dhaliwal Rupinder, G Day Andrew, J Ridley Emma, R Davies Andrew and K Heyland Daren. The author names should be written as Adam M Deane, Rupinder Dhaliwal, Andrew G Day, Emma J Ridley, Andrew R Davies and Daren K Heyland.

\section{Author details}

${ }^{1}$ Intensive Care Unit, Level 4, Emergency Services Building, Royal Adelaide Hospital, North Terrace, Adelaide 5000, South Australia, Australia. ${ }^{2}$ Discipline of Acute Care Medicine, University of Adelaide, Level 5, Eleanor Harrald Building, Frome Road, Adelaide 5000, South Australia, Australia. ${ }^{3}$ Clinical Evaluation Research Unit, Kingston General Hospital, Kingston K7L 2 V7, Ontario, Canada. ${ }^{4}$ Department of Epidemiology and Preventive Medicine, Monash University, The Alfred Centre, Level 6, 99 Commercial Road, Melbourne 3004, Victoria, Australia.

\section{Published: 01 Jul 2014}

\section{References}

1. Adam MD, Rupinder D, Andrew GD, Emma JR, Andrew RD, Daren KH: Comparisons between intragastric and small intestinal delivery of enteral nutrition in the critically ill: a systematic review and meta-analysis. Crit Care 2013, 17:R125.

\section{$10.1186 /$ cc13961}

Cite this article as: Deane et al: Comparisons between intragastric and small intestinal delivery of enteral nutrition in the critically ill: a systematic review and meta-analysis. Critical Care 2014, 18:R138

\footnotetext{
* Correspondence: adam.deane@adelaide.edu.au

'Intensive Care Unit, Level 4, Emergency Services Building, Royal Adelaide Hospital, North Terrace, Adelaide 5000, South Australia, Australia

${ }^{2}$ Discipline of Acute Care Medicine, University of Adelaide, Level 5, Eleanor

Harrald Building, Frome Road, Adelaide 5000, South Australia, Australia

Full list of author information is available at the end of the article
} 